\title{
Consumer car preferences and information search channels
}

\author{
Frank van Rijnsoever ${ }^{\mathrm{a}, *}$, Jacco Farla ${ }^{\mathrm{a}}$, Martin J. Dijst ${ }^{\mathrm{b}}$ \\ a Innovation Studies Utrecht, Copernicus Institute for Sustainable Development and Innovation, Heidelberglaan 2, Utrecht, \\ 3584 CS, Utrecht University, The Netherlands \\ ${ }^{\mathrm{b}}$ Urban and Regional Research Centre Utrecht, Faculty of Geosciences, Utrecht University, Utrecht, The Netherlands
}

\section{A R T I C L E I N F O}

\section{Keywords:}

Car purchase

Involvement

Attitude-behavior gap

Information search

\begin{abstract}
A B S T R A C T
In this paper, we measure the relations between stated and revealed car preferences and the use of information sources in the car-purchasing process, based on a survey of households in the Netherlands. The analysis showed that attitudinal and behavioral constructs are found for 'environmental', 'performance', and 'convenience' preferences, but that there is a 'gap' between attitude and behavior. The results show that people with a positive environmental attitude who also show environmentally friendly behavior have more involvement with cars than people who do not translate their environmental attitude into the corresponding behavior. This leads to the idea that not only environmental knowledge but also involvement with cars is a prerequisite for buying an environmentally friendly car. (c) 2009 Elsevier Ltd. All rights reserved.
\end{abstract}

\section{Introduction}

Eight out of ten citizens in the European Union share the opinion that the type of car and the way people use their cars have important impacts on the environment in the respondent's area (European Commission, 2007). Although 75\% of the Europeans say that they are ready to buy environmentally friendly products, even if these are more expensive, only $17 \%$ are likely to take actions that are directly related to their lifestyles and consumption habits, such as using their cars less and purchasing green products (European Commission, 2008).

These figures support the idea that there is a high awareness about negative environmental impacts of automobility, but this does not translate into changes in car use and purchasing behavior. Studies have been conducted in which the relation between attitudes and environmentally friendly behavior is investigated and all conclude that although attitudes and the corresponding behaviors are related, the explanatory value of attitudes on behavior is limited. Furthermore, it has been shown that the assumption that if people know more about the environmental implications of their behavior, they will act more pro-environmentally, is untenable. On the other hand, it is acknowledged that information provision is a prerequisite for changing environmental behavior.

Environmental innovation in mobility requires the development of cleaner fuels and propulsion techniques on the one hand. On the other hand, the greening of consumption, which includes changes in mobility behavior and also the uptake of environmentally benign innovations, is of paramount importance. In relation to changing behavior, different audiences behave differently and require targeted and/or tailored interventions. A question from the policy domain is thus how to effectively address different target groups. One of the opportunities for policy makers and marketers to effectively convey information to specific groups of car drivers is at the point in time when it can matter most: the moment when people buy a car.

\footnotetext{
* Corresponding author. Tel.: +31302537484.

E-mail address: f.vanrijnsoever@geo.uu.nl (F. van Rijnsoever).
} 
We empirically explore the attitudes that consumers have towards car attributes in the purchase process and what behaviors these consumers displayed when buying their current cars. We also examine whether consumers can be clustered into distinguishable groups on the basis of these attitudes and behaviors. Finally, the consumers' attitudes and behaviors towards car purchasing are combined with a model for pre-purchase information search.

\section{Theory}

According to Ajzen (2005) an attitude is defined as "a disposition to respond favourably or unfavourably to an object, person, institution or event. [...] The main characteristic of attitude is its evaluative nature." Attitude theory (Eagly and Chaiken, 1993; Ajzen, 2005) typically relates attitude to behavior through an intermediary intention construct. Before purchasing a new car, a consumer forms an attitude towards the possibility of owning a car. This attitude can be translated into an intention to buy a specific car, and finally the consumer can act on his intention and take steps to purchase a car. In order to preserve theoretical parsimony in this study we only measure aggregated attitudinal and behavioral constructs, although we recognize the importance of intention as an explanatory construct.

A consumer will have attitudes towards all the attributes of a new car. We are mainly concerned with consumers' attitudes towards environmentally friendly aspects of a car. It is well-known that not all attitudes are translated into behavior; there is an attitude-behavior gap. Such a gap is present with regard to environmental concerns (Owens, 2000; Bartiaux, 2008). Anable et al. (2006) concluded that many barriers obstruct the translation of awareness into travel behavior. These barriers apply at the personal and at the collective level and consist of both subjective and objective factors. At the individual level, important subjective factors are values, norms, perceived behavioral control, instrumental and affective attitudes, identity, and status. The objective individual factors identified by Anable et al. are knowledge/awareness of consequences, habits, and resource constraints. Collective factors include social dilemmas, group culture, and shared norms. Ajzen claims that the more specific the attitude is towards behavior, the smaller the gap becomes. For example, a favorable attitude to waste recycling has a higher correlation with recycling behavior than a favorable attitude towards the environment in general. To measure the attitude-behavior gap we include both the consumers stated and revealed preferences about cars in the purchasing process.

Prior to the actual purchasing of a new vehicle, consumers typically engage in an information search process. Two types of pre-purchase information search can be distinguished: internal search and external search (Blackwell et al., 2001). An internal search is nothing more than a memory scan by the consumer for decision-relevant information. An external search is the consulting of external information sources for decision-relevant information in the purchase process. A consumer can use various external search channels to gather information. Van Rijnsoever et al. (forthcoming) measures the size of the car-related involvement in relation to information search in the car-purchasing process and identify four external information search channels: personal channels, mass media channels, the World Wide Web, and use of retailers. Personal channels refer to the relations of an actor with people from his or her social environment (e.g. friends, family, and colleagues). Mass media channels are the information sources that do not require direct local interaction with the actor; examples are radio, TV, or newspapers. The World Wide Web relates to all information that consumers retrieve from Web pages. Retailers are defined as people who advise consumers about cars as part of their profession.

An important determinant of information search is the consumer's involvement with the product category under investigation (Schmidt and Spreng, 1996). Involvement is the perceived personal relevance of a product to the consumer in terms of needs, values, goals, and interests (Zaichkowsky, 1985). It is strongly related to the prior knowledge and experiences the consumer has with the product category.

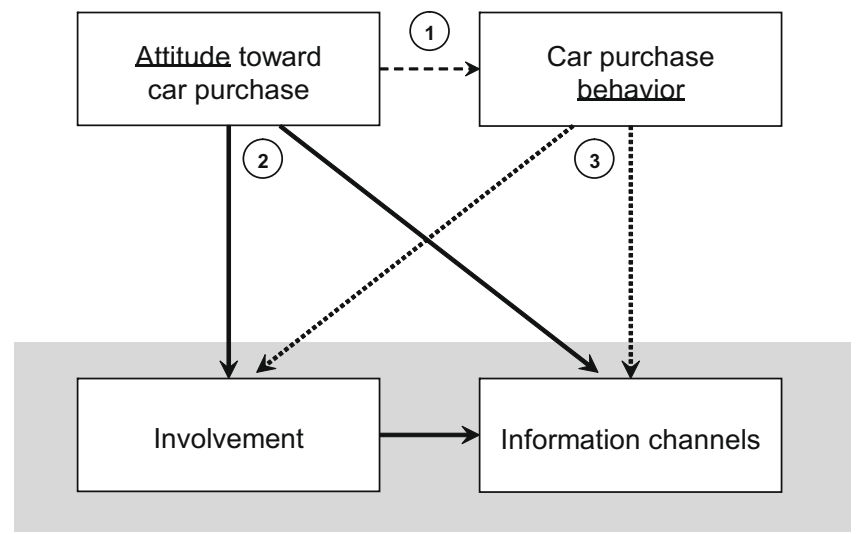

Fig. 1. Schematic presentation of concepts and measured relations. 
Relating attitudinal and behavior constructs to involvement and the use of information search channels leads to the conceptual model displayed in Fig. 1. We expect that different types of attitudes and behaviors can be related to involvement and the use of search channels.

\section{Research design}

\subsection{Data collection and measurement}

In December 2007, during a period of 3 weeks, 1500 questionnaires were personally delivered to households throughout The Netherlands. To ensure a representative sample, the students who collected the data were given quotas for sex and age of the respondents that had to be filled. If there was a car in the household, then the person who was most responsible for the purchase process was asked to fill in the questionnaire. If the person did not want to fill in the questionnaire, another household was included, until 1500 questionnaires were distributed and all quotas were filled. Respondents were told that they were participating in a survey on car use and the environment. If they filled in the questionnaire they could win a gift voucher worth $€ 20$. In this manner, 1392 households owning a car were surveyed. After checking with data from the Dutch Central Statistics Office, the sample turned out to be a good representation of households owning a car. Only the educational level of the respondents turned out to be too high compared to that of the population.

In the questionnaire attitudes were measured with regard to 19 attributes of new cars based on research for the UK Department for Transport (Department for Transport, 2004) in which people were asked what factors are important in deciding which make and model of car to buy. From this listing, factors that are not car attributes were left out, such as 'dealership' and 'personal experience'. Participants could respond on a five-point scale that varied from 'very important' to 'very unimportant' An exploratory principal component analysis revealed that a three-factor solution best fitted the data. This solution was modeled in a confirmatory factor analysis (Table 1 ). The three factors were:

- An environmental attitude: a favorable disposition towards environmentally friendly aspects of a car.

- A performance attitude: a favorable disposition towards elements of a car that enhance driving performance and the image of a car.

- A convenience attitude: a favorable disposition towards elements of a car that enhance the comfort and practicality of a car.

An issue with regard to the measurement of attitudes is the fact that attitudes are not constant; they change with the situational context in which the attitudes arise. The situations in which the questionnaires were filled in did not match the actual car-buying situation in, for example, a showroom. Nijhuis and Spaargaren (2006) argue that the situational context may be as important for the behavioral outcome as the consumer's attitudes and this is one of the reasons why behavioral constructs were also measured. The advantage of measuring behavior is that its measurement is more reliable, since it

Table 1

The measurement models for the attitudinal constructs.

\begin{tabular}{|c|c|c|c|}
\hline Indicator & Explained variance & Latent variable & Model performance \\
\hline $\begin{array}{l}\text { How important do you find the following aspects when } \\
\text { purchasing a new car? (on a one to five-point scale) }\end{array}$ & & & $\begin{array}{l}\text { GFI: } 0.92 \\
\text { NFI: } 0.95\end{array}$ \\
\hline Greenhouse gas emissions & 0.84 & Environment attitude & RMSEA: 0.073 \\
\hline Emission of polluting chemicals & 0.91 & & $X^{2}=1209.54$ \\
\hline The energy label of the car & 0.54 & & $\mathrm{df}=143$ \\
\hline Environmentally friendly materials & 0.65 & & \\
\hline Appearance & 0.63 & Performance attitude & \\
\hline Brand & 0.42 & & \\
\hline The "feeling" you get from the car & 0.37 & & \\
\hline Engine size & 0.35 & & \\
\hline Image & 0.61 & & \\
\hline Speed & 0.45 & & \\
\hline Color & 0.44 & & \\
\hline $\begin{array}{l}\text { Extra accessories on the inside (such as aircon, heated seating, } \\
\text { sunroof) }\end{array}$ & 0.34 & & \\
\hline Extra accessories on the outside (such as metallic paint, fog lights) & 0.45 & & \\
\hline $\begin{array}{l}\text { Electronic products (such as a CD player, DVD player, navigation } \\
\text { system) }\end{array}$ & 0.33 & & \\
\hline Type of car (size, arrangement of the car, etc.) & 0.47 & Convenience attitude & \\
\hline Comfort & 0.35 & & \\
\hline Volume of the car (number of seats, volume of the trunk) & 0.50 & & \\
\hline Length of the car & 0.29 & & \\
\hline Reliability & 0.32 & & \\
\hline
\end{tabular}


Table 2

The measurement models for the behavioral constructs.

\begin{tabular}{|c|c|c|c|}
\hline Indicator & Explained variance & Latent variable & Model performance \\
\hline $\mathrm{CO}_{2}$ reducing tires & 0.32 & Environment behavior & GFI: 0.95 \\
\hline Silent tires & 0.25 & & NFI: 0.93 \\
\hline Econometer/shift indicator & 0.15 & & RMSEA: 0.048 \\
\hline Particle filter & 0.14 & & $X^{2}=847.58$ \\
\hline Leather seats & 0.29 & Performance behavior & $\mathrm{df}=205$ \\
\hline Seat heating & 0.34 & & \\
\hline Top speed & 0.22 & & \\
\hline Fuel economy & 0.03 & & \\
\hline Cruise control & 0.39 & & \\
\hline Automatic gears & 0.17 & & \\
\hline Navigation system & 0.30 & & \\
\hline Four wheel drive & 0.15 & & \\
\hline Hands-free mobile phone application & 0.20 & & \\
\hline Length of the car & 0.06 & & \\
\hline Winter tires & 0.15 & & \\
\hline Airbags & 0.34 & Convenience behavior & \\
\hline Year of build & 0.18 & & \\
\hline Power steering & 0.31 & & \\
\hline Anti-lock breaking system (ABS) & 0.37 & & \\
\hline Air conditioning & 0.41 & & \\
\hline Price & 0.27 & & \\
\hline New/second-hand & 0.18 & & \\
\hline
\end{tabular}

is factual information. The main disadvantage of measuring behavior in a survey is that it relates to behavior in the past. There is no real telling whether the attitudes that we measured were formed because of the past behavior or whether they were formed prior to the behavior. If the attitudes have evolved since the past behavior, this might explain a part of the attitude-behavior gap that we find. As indicators for displayed behavior, the respondents were asked to state a number of characteristics of the car they had most recently bought. ${ }^{1}$ A principal component analysis gave a three-factor solution that corresponded with the attitudinal solution. This solution was modeled in a confirmatory model. The indicators and solutions are provided in Tables 1 and 2.

The involvement construct was measured with six items from the IPCA automobile involvement scale by Bloch (1981). This is a validated scale that measures involvement with automobiles. To measure the use of search channels, questions were asked about the use of various information channels in the process of purchasing a car. Respondents could respond on a fivepoint scale that varied from 'fully disagree' to 'fully agree' (Table 3$)^{2}$

\subsection{Analysis}

A two-step cluster analysis was initially conducted to identify groups of consumers based on the three attitudinal constructs. The same procedure was done to identify consumers based on their displayed behavior. The log-likelihood was used as a distance measure for the clusters. With the help of Schwarz's Bayesian information criterion (BIC), the best cluster solution was determined. The attitude cluster solution and the behavioral cluster solution were compared using a cross tabulation showing the extent to which the two types of clusters correspond, and can thus serve as a measure for the attitude-behavior gap at the population level.

The attitudinal and behavioral constructs were analyzed in relation to involvement and search channels. Pre-testing revealed that analyzing the constructs separately yielded superior results compared to using the cluster solution. In the cluster solution too much valuable information is lost that can help to explain channel use. Therefore the constructs were analyzed separately. Three models were built (see Fig. 1 again). In the first model the attitudinal and behavioral constructs were related to measure the attitude-behavior gap. In the second model the attitudinal constructs were used to predict involvement and search channel use, this extends the by Van Rijnsoever et al. (forthcoming) (indicated by a gray background in Fig. 1). In the third model the behavioral constructs were related to the Van Rijnsoever et al. model. In the models we allowed for covariance among the information channel variables, the attitudinal constructs, and the behavioral constructs. Error-covariances among the indicators were also allowed if the modification indicated that this would improve the model fit. The goodness of fit index (GFI), the root mean square error of approximation (RMSEA), the normalized fit index (NFI) and the model chi-square with the degrees of freedom were used as model performance indicators.

\footnotetext{
1 We only looked at the technical characteristics of the car and did not enquire about the respondent's driving behavior, which is also important for the environmental effects of car driving.

${ }^{2}$ Five-point scales were used rather than three-point scales because they give a larger variety of values of the composite scale. Seven-point scales might be perceived as too complex by respondents.
} 
Table 3

The operationalization of the variables, explained variance of the indicators, and performance indicators of the measurement models.

\begin{tabular}{|c|c|c|c|}
\hline Indicator & $\begin{array}{l}\text { Explained } \\
\text { variance }\end{array}$ & Latent variable & Model performance \\
\hline I enjoy discussing cars with my friends & 0.75 & \multirow[t]{6}{*}{ Involvement } & \multirow{7}{*}{$\begin{array}{l}\text { GFI: } 0.99 \\
\text { NFI: } 0.99 \\
\text { RMSEA: } 0.054 \\
\mathrm{X}^{2}=40.68 \\
\mathrm{df}=8\end{array}$} \\
\hline I get bored when other people talk to me about cars ${ }^{a}$ & 0.29 & & \\
\hline When I'm with a friend, we often end up talking about cars & 0.65 & & \\
\hline I regularly discuss cars with friends & 0.71 & & \\
\hline Cars are nothing more than appliances ${ }^{\mathrm{a}}$ & 0.32 & & \\
\hline $\begin{array}{l}\text { I do not pay much attention to car advertisements in } \\
\text { magazines or on } \mathrm{TV}^{\mathrm{a}}\end{array}$ & 0.42 & & \\
\hline When purchasing a car, I make use of the following information s & urces: & & \\
\hline My own experience from the past & 0.18 & \multirow[t]{3}{*}{ Internal search } & \multirow{17}{*}{$\begin{array}{l}\text { GFI: } 0.93 \\
\text { NFI: } 0.94 \\
\text { RMSEA: } 0.075 \\
X^{2}=783.11 \\
\text { df }=89\end{array}$} \\
\hline The results of a test drive ${ }^{b}$ & 0.33 & & \\
\hline My own knowledge about cars & 0.81 & & \\
\hline My close relatives & 0.33 & \multirow[t]{3}{*}{ Personal channels } & \\
\hline My friends & 0.62 & & \\
\hline $\begin{array}{l}\text { People from my direct environment, for example school or } \\
\text { work }\end{array}$ & 0.53 & & \\
\hline Advertisements and magazines about cars & 0.46 & \multirow{4}{*}{$\begin{array}{l}\text { Mass media } \\
\text { channels }\end{array}$} & \\
\hline I look at other cars in the street & 0.28 & & \\
\hline Television programs about cars & 0.49 & & \\
\hline Radio and television commercials & 0.55 & & \\
\hline Internet websites of the various car brands and manufacturers & 0.68 & \multirow[t]{3}{*}{ World Wide Web } & \\
\hline Internet websites for consumers about cars & 0.64 & & \\
\hline Search engines like Google and Yahoo & 0.45 & & \\
\hline Garage owners & 0.12 & \multirow[t]{4}{*}{ Retailers } & \\
\hline Retailers & 0.36 & & \\
\hline Car salesmen, dealers, or lease companies & 0.41 & & \\
\hline The results of a test drive ${ }^{b}$ & 0.33 & & \\
\hline
\end{tabular}

a Items are reversed scored; means are after reversing the scores.

b This indicator is factorially complex: it was used in both internal search and use of retailers.

Table 4

The cluster solutions for the attitudinal constructs and the behavioral constructs.

\begin{tabular}{|c|c|c|c|c|}
\hline Cluster & Percentage (\%) & Environmental mean & Performance mean & Convenience mean \\
\hline \multicolumn{5}{|l|}{ Attitude } \\
\hline 1 & 15.3 & $-0.42^{* * *}$ & $-1.28^{* * *}$ & $-1.34^{* * *}$ \\
\hline 2 & 18.8 & $-1.33^{* * *}$ & $0.29^{* * *}$ & -0.07 \\
\hline 3 & 46.0 & $0.44^{* * *}$ & -0.03 & $-0.05^{*}$ \\
\hline 4 & 19.9 & $0.57^{* * *}$ & $0.78^{* * *}$ & $1.23^{* * *}$ \\
\hline \multicolumn{5}{|c|}{ Behavior } \\
\hline A & 24.4 & $-0.24^{* * *}$ & $1.08^{* * *}$ & $0.76^{* * *}$ \\
\hline B & 46.1 & $-0.37^{* * *}$ & $-0.52^{* * *}$ & $0.06^{*}$ \\
\hline $\mathrm{C}$ & 13.9 & $2.11^{* * *}$ & $0.72^{* * *}$ & $0.58^{* * *}$ \\
\hline $\mathrm{D}$ & 15.6 & $-0.41^{* * *}$ & $-0.79^{* * *}$ & $-1.88^{* * * *}$ \\
\hline
\end{tabular}

\section{Results}

\subsection{Cluster analysis}

The two-step cluster analysis revealed that for the attitudinal constructs a four-cluster solution would be optimal. Table 4 displays the percentages of cases of each cluster and the cluster means and standard deviations. Since the constructs were standardized variables it is only possible to make claims relative to the average, which is by definition zero. In interpreting the results any number that does not differ significantly from zero $(p>0.05)$ is considered 'average'; all values that have a mean of 0.5 above or below this are 'moderately deviating'; all values that have a mean of $0.5-1.0$ above or below the average are 'high' or 'low deviations'; and all values that have a mean of more than 1.0 above or below the average are 'very high' or 'very low deviations'.

Attitudinal cluster 1 consists of respondents with moderately low environmental attitude scores, and very low scores for performance and convenience attitudes. Cluster 2 has very low environmental attitude and moderately high performance attitude scores. The convenience attitude score is average. Respondents in cluster 3 have a moderately high environmental 
Table 5

The cross tabulation that links the attitudinal clusters to the behavioral clusters.

\begin{tabular}{|c|c|c|c|c|c|c|}
\hline & & \multicolumn{5}{|c|}{ Behavioral clusters } \\
\hline & & $A(\%)$ & $\mathrm{B}(\%)$ & $\mathrm{C}(\%)$ & $\mathrm{D}(\%)$ & Total (\%) \\
\hline \multirow[t]{5}{*}{ Attitude clusters } & 1 & 1.30 & 8.93 & 0.36 & 4.76 & 15.3 \\
\hline & 2 & 6.77 & 7.13 & 2.02 & 2.88 & 18.8 \\
\hline & 3 & 10.66 & 22.69 & 6.41 & 6.20 & 46.0 \\
\hline & 4 & 5.69 & 7.35 & 5.12 & 1.73 & 19.9 \\
\hline & Total & 24.4 & 46.1 & 13.9 & 15.6 & 100.0 \\
\hline
\end{tabular}

attitude score and a moderately low convenience attitude score, although this is negligible. This is by far the largest cluster. Finally respondents in cluster 4 have high scores for environmental and performance attitudes and a very high score for convenience attitude. For this cluster solution, clusters 1 and 4 are rather uninformative. The respondents in these clusters either think that all three aspects are not important or that they are important. There is no strong discrimination between the three constructs. It is thus difficult to tell whether this difference is the result of response biases or real differences between the groups.

The same type of analysis was performed for the behavioral constructs. This also gives a four-cluster solution. The percentages, means, and standard deviations are displayed in Table 4. Behavioral cluster A contains respondents with a moderately low score for environmental behavior, but with very high performance behavior and high convenience behavior scores. Cluster B also shows moderately low environmental behavior and low performance behavior scores; the convenience behavior score is moderately high, but the difference from zero is negligible. This is by far the largest cluster. Respondents in cluster $C$ score very high on environmental behavior and score high on performance and convenience behaviors; this is the smallest cluster. Finally cluster D scores moderately low on environmental behavior, low on performance behavior, and very low on convenience behavior. Again one could ask whether clusters C and D are different from one another, since they do not discriminate between the constructs themselves. However, since these are behavioral measures, the answers are less sensitive to response biases, and so in this case there are real differences between the clusters.

Finally, a cross tabulation that indicates the difference in attitudes and behaviors among the clusters is presented in Table 5 which shows how the respondents from the attitude clustering are distributed over the behavioral clusters. The rows represent the attitude clusters, the columns the behavioral clusters. The cells give the percentages of the sample that have specific combinations of cluster memberships.

Nearly $66 \%$ of the respondents have a positive attitude toward the environment (attitude clusters 3 and 4 ); but only $11.5 \%$ out of these have translated these attitudes into pro-environmental behaviors (members of attitude clusters 3 and 4 who are also in behavioral cluster $\mathrm{C}$ ). This also means that $2.4 \%$ of the population who do not feel that environmental aspects are important, still have relatively environmentally friendly cars (cluster combinations $1 \mathrm{C}$ and $2 \mathrm{C}$ ). Of the $38.7 \%$ of respondents who have a positive attitude toward performance (members of attitude clusters 2 and 4), approximately half show the corresponding behavior (members of attitude clusters 2 and 4 who are also in behavioral clusters A and C; 19.6\% of the population). Further, $18.7 \%$ of the population possess a car that has more performance attributes than average even though they do not deem these attributes to be important. Finally, of the $19.9 \%$ of the population who have a positive attitude towards convenience (members of attitude cluster 4), almost all also have a car that scores above average with respect to convenience $^{3}$ (cluster combinations 4A, 4B, and 4C: $18.6 \%$ of the population). We can thus conclude that on a population level the average attitude-behavior gap is the largest for the environmental constructs and the smallest for convenience constructs.

\subsection{Structural equation modeling}

We now turn to the models in which the different constructs are related to involvement and information search channels. First, we discuss the model that estimates the attitude-behavior gap in terms of explained variance (Table 6). The columns represent the independent variables and the rows the dependent variables. Each cell gives the completely standardized direct effect estimator allowing comparisons of the effect sizes.

Model 1 measures the relationship between the three-attitudinal concepts and the three displayed behavioral concepts on an individual level. As seen from the diagnostic statistics, the model provides a good fit. When looking at the explained variance, there is quite a large attitude-behavior gap, although the result is somewhat different from the results from the cluster solution. As predicted by attitude theory, all corresponding attitude-behavior relationships are significantly positively related. A surprising result is that environmental behavior is predicted better by performance attitude than by environmental attitude, this indicates that there is some form of technology clustering (Van Rijnsoever and Castaldi, 2009). This is the phenomenon that products are adopted in combination with each other. In this case well-performing cars also have more environmentally friendly attributes. The convenience attitude has the weakest relation to environmental behavior. There is a negative relationship between environmental attitudes and the performance of the car owned. A positive relation-

\footnotetext{
${ }^{3}$ To verify these results a two-step cluster analysis was run with the attitude-behavior pairs of constructs. These gave similar results for each construct.
} 
ship is found between convenience attitude and performance behavior. Finally, there is minimal relationship between environmental attitude and convenience behavior; environmental attitude thus has no influence on the level of comfort of the adopted car.

Table 7 presents the direct effects of the model that relates the attitude constructs to involvement and the use of search channels, the model performance indicators show a reasonable fit. Table 8 presents the total effects of this model. The total effects model takes into account the indirect effects, from attitudes through involvement to search channel use. This provides insight into whether or not the relationships found are explained by involvement.

In the model, performance attitude is strongly positively related and environmental and convenience attitudes negatively related to involvement. People with high scores on environmental attitudes generally have less involvement with cars.

Table 8 shows that environmental attitudes are negatively related to internal search, while performance attitude is positively related to internal search. In the direct effects model (Table 7) it can be seen that both these effects are explained by involvement. Convenience attitude is also positively related to internal search in the total effects model. When correcting for involvement, this effect becomes stronger. In the total effects model, a positive environmental attitude is negatively related to the use of personal channels, while a positive performance attitude is positively related to personal channels. The explained variance is, however, very low.

The greatest effect of an attitudinal construct on the use of the search channels in Table 8 is the relationship between performance attitude and the use of mass media. Using mass media emerges as the most effective when addressing consumers with positive attitudes towards performance.

Table 6

The attitude-behavior model.

\begin{tabular}{lllll}
\hline & & Attitude & & \\
\cline { 2 - 5 } & & Environment & Performance & $R^{2}$ \\
\hline Behavior & Environment & $0.21^{* * *}$ & $0.30^{* * *}$ & $0.16^{*}$ \\
& Performance & $-0.16^{* * *}$ & $0.44^{* * *}$ & $0.11^{* *}$ \\
0.23 & $0.20^{* * *}$ & 0.14 \\
\hline
\end{tabular}

GFI: 0.95; NFI: 0.94; RMSEA: 0.026; chi sq.: 1467.19; df: 763.

* $p<0.05$.

** $p<0.01$.

**** $p<0.001$.

Table 7

Direct completely standardized effects of the attitude model.

\begin{tabular}{|c|c|c|c|c|c|c|}
\hline & & \multicolumn{5}{|l|}{ Attitude } \\
\hline & & Environment & Performance & Convenience & Involvement & $R^{2}$ \\
\hline \multirow[t]{6}{*}{ Information Search Channels } & Involvement & $-0.21^{* * *}$ & $0.73^{* * * *}$ & $-0.17^{* * *}$ & & 0.48 \\
\hline & Internal search & -0.06 & -0.05 & $0.28^{* * *}$ & $0.61^{* * *}$ & 0.46 \\
\hline & Personal channels & -0.01 & $-0.14^{*}$ & 0.02 & $0.38^{* * *}$ & 0.10 \\
\hline & Mass media & $0.09^{* *}$ & $0.12^{* *}$ & 0.03 & $0.63^{* * *}$ & 0.51 \\
\hline & World Wide Web & $0.07^{*}$ & -0.06 & $0.12^{* *}$ & $0.46^{* * *}$ & 0.20 \\
\hline & Retailers & 0.03 & 0.03 & $0.10^{*}$ & 0.04 & 0.02 \\
\hline
\end{tabular}

GFI: 0.86; NFI: 0.93; RMSEA: 0.062; chi sq.: 4554.79; df: 734 .

${ }^{*} p<0.05$.

${ }^{* * *} p<0.01$.

*** $p<0.001$

Table 8

Total completely standardized effects of the attitudes model.

\begin{tabular}{|c|c|c|c|c|c|}
\hline & & \multicolumn{4}{|l|}{ Attitude } \\
\hline & & Environment & Performance & Convenience & $R^{2}$ \\
\hline \multirow[t]{6}{*}{ Information Search Channels } & Involvement & $-0.21^{* * * *}$ & $0.73^{* * *}$ & $-0.17^{* * *}$ & 0.48 \\
\hline & Internal search & $-0.19^{* * *}$ & $0.39^{* * *}$ & $0.18^{* * *}$ & 0.27 \\
\hline & Personal channels & $-0.09^{* *}$ & $0.14^{* * *}$ & -0.04 & 0.02 \\
\hline & Mass media & -0.04 & $0.58^{* * *}$ & $-0.08^{*}$ & 0.30 \\
\hline & World Wide Web & -0.03 & $0.28^{* * *}$ & 0.04 & 0.09 \\
\hline & Retailers & 0.02 & 0.06 & $0.09^{*}$ & 0.02 \\
\hline
\end{tabular}

\footnotetext{
${ }^{*} p<0.05$.

** $p<0.01$.

*** $p<0.001$.
} 
Table 9

Direct completely standardized effects of the behavior model.

\begin{tabular}{|c|c|c|c|c|c|c|}
\hline & & \multicolumn{5}{|l|}{ Behavior } \\
\hline & & Environment & Performance & Convenience & Involvement & $R^{2}$ \\
\hline \multirow[t]{6}{*}{ Information Search Channels } & Involvement & -0.05 & $0.62^{* * *}$ & $-0.33^{* * *}$ & & 0.16 \\
\hline & Internal search & 0.08 & 0.15 & 0.00 & $0.56^{* * *}$ & 0.42 \\
\hline & Personal channels & $-0.16^{*}$ & $0.26^{*}$ & $-0.23^{*}$ & $0.25^{* * *}$ & 0.13 \\
\hline & Mass media & -0.06 & -0.01 & $0.16^{*}$ & $0.69^{* * *}$ & 0.50 \\
\hline & World Wide Web & -0.04 & 0.08 & -0.01 & $0.40^{* * * *}$ & 0.18 \\
\hline & Retailers & -0.06 & 0.11 & -0.03 & 0.04 & 0.01 \\
\hline
\end{tabular}

GFI: 0.95; NFI: 0.93; RMSEA: 0.022; chi sq.: 1451.90; df: 865 .

* $p<0.05$.

** $p<0.01$.

*** $p<0.001$.

Table 10

Total completely standardized effects of the behavior model.

\begin{tabular}{|c|c|c|c|c|c|}
\hline & & \multicolumn{4}{|l|}{ Behavior } \\
\hline & & Environment & Performance & Convenience & $R^{2}$ \\
\hline \multirow[t]{6}{*}{ Information Search Channels } & Involvement & -0.05 & $0.62^{* * *}$ & $-0.36^{* * *}$ & 0.16 \\
\hline & Internal Search & 0.05 & $0.49^{* * *}$ & -0.20 & 0.15 \\
\hline & Personal channels & $-0.17^{*}$ & $0.41^{* * *}$ & $-0.32^{* * *}$ & 0.08 \\
\hline & Mass media & -0.09 & $0.42^{* * * *}$ & -0.09 & 0.10 \\
\hline & World Wide Web & -0.07 & $0.33^{* * *}$ & -0.15 & 0.05 \\
\hline & Retailers & -0.06 & $0.13^{* * *}$ & $-0.04^{* * *}$ & 0.01 \\
\hline
\end{tabular}

${ }^{*} p<0.05$.

*** $p<0.01$.

*** $p<0.001$.

Another search channel that is strongly positively related to performance attitude is the Internet. Again this relationship is explained by involvement. Interesting in the direct effects model is that under the influence of involvement, environmental attitude and convenience attitude become significant. The implications of these findings will be discussed in the next section. Finally the use of retailers is only related to convenience attitude. However, this relationship is very small and not affected by involvement.

Table 9 presents the direct effects of the model that relates the behavioral constructs to search channel use, while Table 10 shows the total effects. Again the diagnostic statistics reveal a good fit. There is a positive relationship between performance behavior and involvement and a negative relationship between convenience behavior and involvement. These relationships are the same as in the attitude model. In contrast to the attitude model, there is no negative relationship between environmental behavior and involvement. ${ }^{4}$ This means that consumers who actually display environmentally friendly behavior have more involvement with cars than people who only have environmental friendly attitudes.

In the total effects model, there is a positive relationship between performance behavior and internal search that is entirely explained by involvement in the direct effects model. Personal channels are related positively to performance behavior and negatively to environmental and convenience behavior in the total effects model. People with higher scores on environmental and convenience behavior make less use of personal channels in the search process. The relationship with environmental behavior is similar to the one found in the attitude model.

The model also shows a positive relationship between performance behavior and the use of mass media that is explained by involvement in the direct effects model. Furthermore, a positive relationship between convenience behavior and mass media search appears. There is also a positive relationship between performance behavior and Internet-search that is again explained by involvement.

Finally there is a very small positive relationship between performance behavior and the use of retailers and a negative relationship between convenience behavior and use of retailers in the total effects model. With regard to the use of retailers, both the attitude and behavior models explain the concept very poorly.

\footnotetext{
4 This is possibly because performance attitude is positively related to environmental behavior. Since performance attitude is also positively related to involvement, this could explain the relationship between involvement and environmental behavior. However, an additional analysis that controlled for this aspect revealed that this is not the case.
} 


\section{Conclusions}

The results show that the size of the attitude-behavior gap varies per construct. It is possible that the differences are due to the clustering procedure, but the still widely held belief that environmental choices involve certain sacrifices financially or in comfort or performance may also explain part of the large gap between environmental attitude and behavior.

The results imply policy measures for two target groups that result from the clustering procedure: consumers with unfavorable attitudes and behaviors towards the environment, and consumers with favorable attitudes but unfavorable behaviors towards the environment.

With regard to the first group: the attitude models reveal that there is no positive relationship between environmental attitude and a particular search channel. There is a strong relationship between the performance constructs and the use of mass media channels and the Web. Sending tailored information through these channels about new technical developments that improve environmental performance while maintaining car performance can help to promote positive attitudes toward such new developments.

With regard to the second group: We find that people who translate their environmentally friendly attitude into environmentally friendly behavior are more involved and therefore do know more about cars. This indicates that in order to stimulate people to translate their attitudes into behavior, it is important to get the public both involved with car technology and informed about environmental problems.

\section{References}

Ajzen, I., 2005. Attitudes, Personality and Behavior. Open University Press, Milton Keynes.

Anable, J., Lane, B., et al., 2006. An Evidence Base Review of Public Attitudes to Climate Change and Transport Behaviour. Final Report. The Department for Transport, London.

Bartiaux, F., 2008. Does environmental information overcome practice compartmentalisation and change consumers' behaviours? Journal of Cleaner Production 16, 1170-1180.

Blackwell, R.D., Miniard, P.W., et al., 2001. Consumer Behavior. Harcourt College Publishers, Forth Worth.

Bloch, P.H., 1981. An exploration into the scaling of consumers' involvement with a product class. Advances in Consumer Research 8, 61-65.

Department for Transport, 2004. Assessing the Impact of Graduated Vehicle Excise Duty - Quantitative Report. Department for Transport, London.

Eagly, A.H., Chaiken, S., 1993. The Psychology of Attitudes. Harcourt Brace Jovanovich College Publishers, Forth Worth.

European Commission, 2007. Flash Eurobarometer. Attitudes on Issues Related to EU Transport Policy. European Commission, DG Energy and Transport, Brussels.

European Commission, 2008. Special Eurobarometer. Attitudes of European Citizens Towards the Environment. European Commission, DG Environment, Brussels.

Nijhuis, J., Spaargaren, G., 2006. Car Purchasing as a Social Practice at the Consumption Junction. Launch Conference of the Sustainable Consumption Research Exchange Network (SCORE!), Wuppertal.

Owens, S., 2000. 'Engaging the public': information and deliberation in environmental policy. Environment and Planning A 32, 1141-1148.

Schmidt, J.B., Spreng, R.A., 1996. A proposed model of external consumer information search. Journal of the Academy of Marketing Science 24, $246-256$.

Van Rijnsoever, F.J., Castaldi, C., 2009. Perceived technology clusters and ownership of related technologies: the case of consumer electronics. Journal of the American Society for Information Science and Technology 60, 381-392.

Van Rijnsoever, F.J., Dijst, M.J., Castaldi, C., 2009. Leaving no stone unturned: the determinants of information channel use during the automobile purchase process. ISU Working Paper Series: No. 09-06, Utrecht University.

Zaichkowsky, J.L., 1985. Measuring the involvement construct. Journal of Consumer Research 12, 341-352. 